\title{
Global Climate Games: How Pricing and a Green Fund Foster Cooperation
}

Peter Cramton and Steven Stoft ${ }^{1}$

1 December 2011 (from 14 August 2011)

\begin{abstract}
The most efficient global climate policy is to price carbon. The Kyoto-Copenhagen agenda was intended to do this with a system of international cap and trade. We view these negotiations as a game in which countries choose their quantity targets based on self interest. Like the analogous public-goods game, in which countries choose their abatement levels, we find this game leads to uncooperative behavior and suggest that this is why the Kyoto approach inevitably failed.

By contrast, a game in which all countries vote for a global quantity target or a global price target can lead to a highly cooperative choice of target. However, the assignment of responsibilities for a global quantity target stymies implementation of a global cap. The global-price-target game largely overcomes this barrier, because a uniform global price provides a focal point for cooperation. However low-emission countries apparently prefer a much lower global-price than more prosperous countries unless a Green Fund is implemented. A game that couples such a fund to the global price target can largely overcome this barrier to cooperation. We describe such a game along with its equilibrium outcome, which promises to be inexpensive and cooperative.
\end{abstract}

Keywords: climate change, cap and trade, green fund, international environmental agreement

\section{Introduction}

The most effective climate policy to date has been carbon pricing, albeit in the disguise of OPEC's high oil prices from 1974 through 1984. These prices reset the world's growth path for carbon emissions, and to this day that path remains lower. In Europe, high prices for oil-based carbon emissions - high taxes on gasoline-remain in effect and effective. Pricing is effective because it rewards every conservation strategy and not just the few currently in favor with regulators. And, if pricing is uniform, it works efficiently by purchasing all and only those abatements that cost less than the price.

\footnotetext{
${ }^{1}$ Peter Cramton is Professor of Economics at the University of Maryland and an expert on market design; Steven Stoft is Director of the Global Energy Policy Center and the author of Carbonomics. Their research on climate policy can be found at www.global-energy.org/lib and www.cramton.umd.edu/papers/climate.
} 
At the Kyoto and Copenhagen climate summits, the world attempted to negotiate a system for pricing carbon globally. But, rather than choose a global price, the focus was on negotiating individual national caps. Trading carbon credits issued under the caps would then have established a uniform global price. Although the point of international cap and trade is the efficiency of a uniform price, it was the caps that captured the imaginations of environmentalists. As Fred Krupp, president of the Environmental Defense Fund, said to the Wall Street Journal, "You've heard a thousand times that the whole point [of a cap] is to send a price signal." But his point was that we had been misinformed a thousand times, and he concluded, "The whole point is really a declining cap. The cap drives innovation which lowers the costs." ${ }^{2}$ But, no inventor cares about a cap, except that the cap will raise the price of carbon, which will make his carbon-cutting invention profitable. It is the price, and only the price, that changes behavior.

Caps are also seen as the only possible basis for a "legally binding agreement," but President Obama summed up the situation nicely at the end of the Copenhagen conference when he said "Kyoto was legally binding and everybody still fell short anyway." Although an exaggeration, in the absence of a world government, the point is well taken.

Finally, the focus on caps has made a fetish of selecting the true "scientific" cap for the next fifty years. Strangely, each new "scientific" answer is the numerological focal point of some popular movement $-80 \%$ by $2050,20 \%$ by 2020 , or $350 \mathrm{ppm}$ of $\mathrm{CO}_{2}$.

Together, these two misconceptions, that caps directly control individual behavior and that they are the only basis for certainty, along with the numerical fetish, have had a devastating effect on climate negotiations. They have distracted from the real problem facing the world, which is how to induce cooperation in the most uncooperative of games - a public-goods game with many players facing distant and uncertain global payoffs.

As this paper will show, the game of negotiating caps is doomed to failure because it punishes cooperative behavior at the bargaining table and rewards the free-riding behaviors that are the heart of the climate problem. Because these capping fallacies downplay the benefits of carbon pricing, the failure of the Kyoto-Copenhagen agenda has led to the abandonment of the global pricing objective in favor of idiosyncratic and inefficient subsidies.

This paper takes a more optimistic view of the Kyoto failure. We view national caps as an inherently divisive negotiating goal, so we do not condemn the players as do environmentalists. Instead we find fault

\footnotetext{
${ }^{3}$ The Wall Street Journal, “EDF's Fred Krupp: On Cap-and-Trade, Offsets, and Indiana Grandmothers,” 19 March 2009.
} 
with the game of negotiating caps. ${ }^{3}$ Our prescription is to replace the game with one that directly negotiates a global price. A design based on a common price instead of on individual caps, if properly structured, can dramatically change the incentives of the players by aligning their interests. After all, they do have a shared interest, and that interest should be brought to the fore.

The first part of the paper focuses on problems with the game of international cap and trade. The root of these problems is that there is no international government, so countries choose their own caps according to their self interest. Although global carbon trading will increase efficiency no matter what caps are chosen, this game may not increase the abatement level over what would occur without a treaty (Helm 2003; Holstmark and Sommervoll 2008).

The second part of the paper focuses on an alternative approach to negotiating a global carbon price. We first consider a world with identical countries. In this setting, voting for either a global cap or a global price would foster cooperation. However, in a less symmetrical world, voting for a global price fosters cooperation much more effectively. When national income diversity is included in the game, a Green Fund becomes necessary to enhance cooperation, because low-emission (poor) countries generally favor a low global price target. To maintain cooperation, the Fund must be coupled to the level of the price target.

To overcome a common misperception, we note from the outset that international commitments to a global price target can be met as well with national cap-and-trade policies as with carbon taxes, since both policies put a price on carbon emissions. National pricing uncertainties under cap-and-trade can be handled through trading and averaging procedures similar to those used for quantity uncertainties under cap-and-trade (Cooper 2008; Cramton and Stoft 2009; Stiglitz 2010).

\section{The International Cap-and-Trade Game}

A central goal of the Copenhagen Summit was to induce countries to accept quantitative emission targets that would remain in effect for many years, although they would change in predetermined ways. Essentially, the summit can be viewed as a one-shot game; players would make simultaneous movescommitments to caps, and then, depending on these moves, payoffs would follow. Of course reality is far more complex, and much too complex for formal analysis, so this paper will model cap-and-trade and various other games as if they were simple-one shot games that play out in subsequent years according to the moves made at the beginning.

\footnotetext{
${ }^{3}$ Barrett (1994) argues that even though all countries have an incentive to free ride, "countries have incentives to develop institutions which can punish free riding." Rand et al. (2009) find experimentally that "reward is as effective as punishment for maintaining public cooperation" in a public goods game. We suggest here that the failure of negotiations is not due to the tendency to free ride, but rather to the absence of treaty design elements to counter this tendency.
} 
The reluctance of countries to sign a strong treaty at Copenhagen indicates that signing would have left most countries feeling some obligation to comply. Moreover, treaties could be designed to include inducements to comply, and we will discuss some of these later. For these reasons, consideration of oneshot games appears to be relevant, and it provides a way of comparing the different games in a simple standardized manner. We will apply this approach to all of the games considered.

The international cap-and-trade game consists of each country picking a voluntary target, and agreeing to meet that target either directly or by purchasing carbon credits from other countries that exceed their targets. We also make the usual game-theory assumption that all countries act in their own self interest.

It might seem that every country would adopt a cap of zero in an attempt to do nothing but free ride. The outcome is not so dismal. To understand why, consider the global public-goods game in which each country adopts its own carbon-abatement policy, and there is no trade. Emissions abatement is a public good - that is, any abatement by one country affects every country just as if that country had abated on its own. Suppose there are eight countries and that a ton of abatement would benefit four of them by $\$ 5$ and four of them by $\$ 20$, and hence would benefit the world by $\$ 100$. Then four will set caps or taxes to achieve a domestic carbon price of $\$ 5$ and the other four will implement a carbon price of $\$ 20$. Since a ton of abatement is worth $\$ 100$ to the world as a whole, these low prices fall far short of the efficient global price of abatement.

In the global cap-and-trade game, carbon trading, in the same eight-country world, will lead to a single global price for carbon instead of two prices. All countries will abate until their marginal cost of abatement equals that single carbon price. This is the condition for globally efficient abatement. Hence, abatement will be more efficient under a global cap-and-trade game than under an uncoordinated publicgoods game. In the public-goods game, actual abatement levels are selected to maximize national net benefits, while in the cap-and-trade game, targets are also selected to maximize national net benefit, but this now takes account of permit trading.

It is helpful to compare both the public-goods game and the cap-and-trade game with the optimal outcome. All three of these are closely related to the country-specific net-benefit functions which, for the sake of simplicity, we specify as

$$
N B_{j}=b_{j} A-c_{j} A_{j}^{2}+P \cdot\left(A_{j}-T_{j}\right) \text {, where } A=\sum_{i=1}^{N} A_{i} .
$$

The first term gives the climate benefit which increases with total global abatement, $A$, which, in turn, increases with $A_{j}$. The second term gives the cost of abatement, which increases quadratically (a typical assumption). The third term, present only in the cap-and-trade game, represents the gains from selling 
carbon credits when a country's abatement differs from its target. The condition for globally optimal abatement and the rules of the games are given in Table 1.

Table 1. Definitions of Optimization by Model

\begin{tabular}{ll}
\hline Model & Definition \\
\hline Optimal Cooperation & Choose all $A_{j}$ to maximize $\sum N B_{j}$. (no trade) \\
Public-Goods Game & Countries choose $A_{j}$ to maximize $N B_{j}$ for each country $j$. (no trade) \\
Cap-and-Trade Game & Countries choose $T_{j}$ to maximize $N B_{j}$ with $2 c_{j} A_{j}=P$, for all $j$. \\
\hline
\end{tabular}

Note that when countries choose $A_{j}$ or $T_{j}$ they assume their choice will not affect the choices of other countries. This is the condition for a Nash equilibrium. In the specific game we will analyze first, Country 1 has $b_{j}=1$ and $c_{j}=1$, while Country 2 has $b_{j}=2$ and $c_{j}=2$. From these values the outcome of the game can be determined, as shown in Table 2.

Table 2. A Two Country Example of the International Cap-and-Trade Game

\begin{tabular}{c|ccc|ccc|cccc}
\hline \multirow{2}{*}{$j$} & \multicolumn{3}{|c|}{ Optimal Abatement } & \multicolumn{3}{|c|}{ Public-Goods Game } & \multicolumn{4}{c}{ Cap-and-Trade Game } \\
\cline { 2 - 11 } & $A_{j}$ & $M C_{j}$ & $N B_{j}$ & $A_{j}$ & $P_{j}=M C_{j}$ & $N B_{j}$ & $T_{j}$ & $A_{j}$ & $P=M C_{j}$ & $N B_{j}$ \\
\hline 1 & 1.50 & 3 & 0 & 0.5 & 1.0 & 0.75 & 0.38 & 0.75 & 1.5 & 1.13 \\
\hline 2 & 0.75 & 3 & 3.38 & 0.5 & 2.0 & 1.50 & 0.75 & 0.38 & 1.5 & 1.41 \\
\hline Total & $\mathbf{2 . 2 5}$ & & 3.38 & $\mathbf{1 . 0}$ & & 2.25 & 1.13 & $\mathbf{1 . 1 3}$ & & 2.53 \\
\hline
\end{tabular}

$A_{j}$ is country $j^{\prime}$ s abatement. $M C_{j}=2 c_{j} A_{j}$, its marginal cost of abatement. $N B_{j}$ its net benefit, and $T_{j}$ its abatement target.

Notice the highlighted total abatement levels. Abatement is below optimal in both games, and it would be much lower with more countries. But, even though countries act purely in their self interest in both games, abatement is greater in the cap-and-trade game. The efficiency gains from carbon trading prevail, and the world is better off. Cap and trade succeeds in this example because Country 2 gains the most benefit from abatement but finds it most expensive to abate. Trade allows it to buy abatement from Country 1 , which benefits less from abatement, but can abate more cheaply.

Changing the parameters to $b_{j}=1$ and $c_{j}=3$ for Country 1 , and to $b_{j}=2$ and $c_{j}=1$ for Country 2, causes the cap-and-trade game to reduce abatement, and to increase emissions. In fact, Country 1 , which sees little benefit from abatement and has a high cost of abatement, simply sets a negative target and profits from selling essentially fraudulent carbon credits. A negative abatement target is simply an emissions cap set higher than "business as usual," the amount that would have been emitted without a carbon policy. This might be accompanied by an exaggeration of business-as-usual emissions or by a justification based on historically low emissions. A negative abatement target is an 
example of the "additionality" problem made famous by the U.N.'s Clean Development Mechanism. These two examples do not prove the cap-and-trade game a failure, but a simple theoretical result does.

Proposition 1. In a global cap-and-trade game, with $N$ countries and global carbon price, $P^{*}$, if the marginal benefit of abatement is constant, $P^{*}$ equals $1 / N$ times the optimal price. ${ }^{4}$

Although the cap-and-trade game shows little promise, it does prove that changing the game from the public-goods game to the cap-and-trade game can, under the right circumstances, improve cooperation. Since this is possible, perhaps a different game can induce even more cooperation.

\section{Cheating}

"Gaming the rules" means taking advantage of the rules in a way that is detrimental to the collective outcome and unexpected by the designers of the game. Setting low targets to profit from carbon trade is a form of gaming the cap-and-trade rules. This possibility has been fully accounted for in the above analysis. Cheating is breaking the rules, and that will be considered now.

The most obvious way for a country to cheat would appear to be the selling of fraudulent carbon credits. But what would be the point? A country could set its target at 100 and abate by 100 but sell 10 carbon credits. But why not just set the target at 90 and sell the same 10 carbon credits without cheating? There is no advantage to this form of cheating, so it would not change the outcome.

But, a subtler form of cheating, if left unchecked, would lead to a surprising outcome (Godal and Holstmark 2011). Private abaters have a different objective than the countries in which they operate. In the example of Table 2, an abater in Country 1 will gain 1.5 monetary units per ton abated from the global carbon price. However, because $b_{1}=1$, Country 1 gains only 1 unit worth of climate benefit. Consequently, the country would prefer that its private abaters abate less, but it will not want to lose revenues from selling carbon credits abroad. This can be accomplished at no cost by (1) subsidizing emissions or fossil fuel, which will reduce abatement, and then (2) reducing its target by the same amount. ${ }^{5}$ Similarly, a policy of taxing fossil fuels will be found to benefit Country 2. This form of cheating adds a new strategic parameter, the emissions subsidy rate, $s_{j}$, (negative values indicate a tax).

The result will be that Country 1 abates less, and Country 2 more, than shown in Table 1 under capand-trade. Perhaps not so surprisingly, if this form of cheating is carried out to the optimal extent by each country, the resulting national abatements will be identical to those found in the public-goods game. There will, however, still be carbon trading.

\footnotetext{
${ }^{4}$ See the online Appendix at www.global-energy.org/lib/11-01. A similar result holds for decreasing marginal benefit.

${ }^{5}$ Such subsidies are transfers of wealth with no net social cost other than their indirect effect on the climate.
} 
Table 3. The Table-1 Games with Cheating in the Cap-and-Trade Game

\begin{tabular}{|c|c|c|c|c|c|c|c|c|}
\hline \multirow[b]{2}{*}{$j$} & \multicolumn{3}{|c|}{ Public-Goods Game } & \multicolumn{5}{|c|}{ Cap-and-Trade Game with Emission Subsidies } \\
\hline & $A_{j}$ & $P_{j}=M C_{j}$ & $N B_{j}$ & $T_{j}$ & $s_{j}$ & $A_{j}$ & $P^{*}=M C_{j}$ & $N B_{j}$ \\
\hline 1 & 0.5 & 1 & 0.75 & 0.33 & 0.67 & 0.5 & 1.67 & 1.03 \\
\hline 2 & 0.5 & 2 & 1.50 & 0.67 & -0.33 & 0.5 & 1.67 & 1.22 \\
\hline Total & 1.0 & & 2.25 & 1.00 & & 1.0 & & 2.25 \\
\hline
\end{tabular}

As seen in Table 3, countries will choose exactly the same abatement levels as in the public-goods game. Country 1 will see the global carbon price as too high at 1.67 monetary units, when it would have chosen a price of 1 on its own, as seen in the public goods game. So Country 1 subsidizes its domestic price of carbon back down to 1 . The result is that the Country 1 abates at its public-goods level and targets even less abatement and sells carbon credits to the more ambitious country. This strategy seems similar to some real-world bargaining positions.

The most important conclusion to draw from this analysis is that surreptitious fossil subsidies can undermine cap-and-trade even when quantities are monitored perfectly. Hence, enforcement of efficient cap-and-trade rules require intra-country monitoring of the carbon price level, just as does enforcement of harmonized carbon prices.

\section{Full Cooperation in a Symmetrical World}

Suppose the world were divided into $N$ identical countries. In such a world, there would be no trade under global cap-and-trade, and the outcome would be identical to the public-goods game. The price would be $N$ times too low. ${ }^{6}$ However, two simple games could help such a world achieve full cooperation: the global-cap game and the global-price game. To understand them, it is important to see that choosing a global price is equivalent to choosing a global cap. A global cap with efficient trade will result in a uniform global price, and that price, as discussed above, is what will drive abatement. Hence if the same price is imposed without the cap, the same abatement will result. So it makes no difference whether a price, or the cap that induces that price, is chosen.

The treaty for these games would specify that the each country votes on the global price or quantity (that is, reports a desired value) and the least-stringent vote will determine the outcome of the electionthe global target. Also, if the global cap is $Q$, each country will accept a cap of $Q / N$, or if the global price is $P$, each country must set a carbon price of $P$. As previously mentioned, this outcome will be enforced.

\footnotetext{
${ }^{6}$ This assumes the marginal climate benefit decreases with abatement. See the online Appendix at www.globalenergy.org/lib/11-01.
} 
Why do these games produce an optimal outcome while the public-goods game and the international cap-and-trade game fail? In all games, countries will maximize their own net benefit functions, but in the global-cap game, each country will vote as if it were controlling the abatement level of the world and not just its own abatement level. So each country solves the following problem:

$$
\text { Choose } A \text { to maximize } N B_{j}(A)=b_{j} A-c_{j}\left(A_{j}\right) \text {, where } A_{j}=A / N \text {. }
$$

Since $A=N \cdot A_{j}$, this is the same as choosing $A_{j}$, as in the public-goods game, but having it affect total abatement $A$ by $N$ times more than in that game. This magnifies each country's incentive to raise $A_{j}$ by exactly the amount needed to reach the optimal level of abatement. Hence ever country votes for the optimal $A$, and that prevails.

Both games select the fully cooperative price and abatement levels in this symmetric world. But, let us now introduce a bit of asymmetry. Suppose two countries have the same income and population, but one has abundant hydro resources and a moderate climate. The other is hot and humid, so it uses 50 percent more electricity and has few renewable resources. The only obvious way to share a global cap is to require both to reduce emission by the same percent. But this could easily cost the hot and humid country far more than the country with more renewable resources and less need for power. Why should the hotter country accept this bargain? It should not. So the only obvious allocation of caps will fail, and this will undoubtedly lead to extensive bickering over the correct sharing formula.

By contrast, the assignment of equal carbon prices will impose a more equitable burden. The global carbon price will be the same as under cap and trade, so the hot country will abate the same amount. ${ }^{7}$ But unlike with proportional capping, it will have no need to spend large sums paying luckier countries for carbon credits to meet its cap. As even more complex national differences are considered, the equal-price rule maintains its advantage in perceived fairness because it is closer to an equal effort rule, and does not require payments to other countries based on their luck with natural resources, climate and geography.

This conclusion seems not at all surprising and we suspect that the fixation on quantity rules has persisted simply because they provide the false comfort associated by some with "command and control." In fact one of us was reprimanded by an official of Environment Canada for impugning cap and trade with the nearly blasphemous claim that it was not command and control. Viewing caps as controls explains why they are seen as strong, and prices are seen as ineffective. But as demonstrated, in the international cap-and-trade game, where there is no central authority, caps are anything but strong. So we now leave quantities behind and turn to questions of cooperation.

\footnotetext{
${ }^{7}$ There will be some differences depending on what fossil-fuel taxes existed before the global climate policy (Hoel 1992).
} 


\section{A Treaty as a Focal Point}

Except for the public-goods game, which requires no treaty, the games considered so far begin with a treaty which lacks commitments, then players make voluntary commitments and carry them out. This two-step process is itself a source of cooperation when compared with, for example, the Copenhagen process. In that process, the treaty and commitment steps were unified. This is like attempting to adopt a constitution for a country and pass the tax laws all in one step. It is far easier to agree on the design of the constitution if tax rates are not part of the initial discussion.

But even agreeing on a design without commitments is difficult. For example, we have argued that a design for allocating a global cap is inherently difficult. The problem is not that reasonable designs are hard to come by, but rather that they are hard to agree on. Schelling (1960) illustrated this with his classic game of two people trying to meet up in New York on a certain day without communicating. Coordination is the problem, and Schelling argues (1960) that a focal point - "any key that is mutually recognized as the key" - can greatly increase the chance of the players acting cooperatively. The failure of the global-cap game is, in large part, due to the absence of a focal point. Unfortunately, although a uniform global price is a remarkably strong focal point, ${ }^{8}$ it is not strong enough to provide a complete solution to the problem of coordination in a realistic global-price-target game.

A treaty, if it seems natural and gains prominence, may also provide a focal point. There have been many attempts by environmental groups to generate such focal points, most often based on numerology, as previously mentioned. While these can have mass appeal, they help little with the real problems of cooperation. Consequently, more substantive focal points (such as a uniform global price) are needed in the arena of international negotiations.

The idea of Green-Fund payments appears to have become focal among a substantial circle of climate policy experts. The idea that a treaty should take effect only when signed by participants with a certain percent of global emissions is widely accepted. And, selecting a value by agreement of a supermajority is also a natural building block for a treaty. So the goal should be to develop a treaty built around a core that can serve as a focal point for cooperation. It should also provide good incentives and some natural self-enforcement. We think of such a treaty as the rules of a game and suggest analyzing it in this light.

\section{The Green-Fund Concept}

The global-price game just discussed would have a decent chance of gaining strong commitments were it not for two problems. First, some countries with large gas and oil resources will likely prefer climate

\footnotetext{
${ }^{8}$ It is not a particular price that is the focal point, but rather the view that all countries should implement the same price.
} 
change to a loss of export revenues. They will vote for a carbon price of zero. For this reason, the treaty must specify that the global price will be set by a supermajority of perhaps 60 or 70 percent (by total emissions). ${ }^{9}$ While this aspect of the treaty deserves attention, we will focus on the other problem, which is caused by the variation in national incomes and emission levels.

A Green Fund, which makes equity transfers from rich to poor countries, has been widely proposed as a way of accommodating international income disparities and the corresponding differences in emissions levels. A Green-Fund rule should be simple and appear naturally suited to its task in order to improve its chance of being accepted as focal. We propose basing it on emissions per capita because that will turn Green-Fund payments into an incentive for all countries to reduce their emissions (Cramton and Stoft 2010). Countries that reduce emissions will either pay less or be paid more as can be seen from the formula

$$
\text { Green-Fund payment received }=G \cdot \Delta E_{j} \cdot P^{T},
$$

where $G$ determines the strength of the Green Fund, $\Delta E_{j}$ is a country's emissions shortfall relative to the global average, and $P^{T}$ is the global price target. More specifically, the emissions shortfall is given by $\Delta E_{j}=\left(e-e_{j}\right) n_{j}$, where $e$ is global emissions per capita, $e_{j}$ is the country's emissions per capita, and $n_{j}$ is its population. In the example to follow, $P^{T}$ will be about $\$ 26 /$ ton, and the Green-Fund will pay about $\$ 1.10 /$ ton of saved emissions.

The linkage to the global price target, $P^{T}$, is essential for bringing cooperation to an otherwise contentious process of determining both the strength of the Green Fund, $G$, and the global price target, $P^{T} .{ }^{10}$ The parameter $G$ will be selected first, and then countries will vote for their preferred value of $P^{T}$, with the lowest vote within the designated supermajority determining the outcome. This provides an answer to how large the Green-Fund payments should be. They should be set to maximize the lowest vote for $P^{T}$ within the supermajority and thereby maximize the selected global price target. The countries that will naturally be motivated to choose such a $G$ will be those with close-to-average emissions per capita, because they participate least in the Green Fund and so are concerned only with climate policy. One possible selection mechanism would be to let the ten or twenty countries with closest-to-average emissions name their preferred $G$ and then use the median value. Such countries should not select too high a value for $G$, as that would discourage high-emission countries from favoring a high value for $P^{T}$, and should not select too low a value, as that would discourage low-emission countries.

\footnotetext{
${ }^{9}$ One possible rule would be that if $65 \%$ were the threshold, then the set of countries covering at least $65 \%$ of emissions and having the highest minimum preference for $P^{T}$ would initially ratify the treaty.

${ }^{10}$ This implementation of the Green Fund encourages cooperation while the standard implementation and the present Clean Development Mechanism, both encourage poor countries to avoid cooperating with a global pricing mechanism.
} 


\section{The Green-Fund Game}

The point of the Green Fund is to induce low-emission countries to agree to adopt higher domestic carbon prices. So, in order to test how well it works, we must model the propensity of low-emission countries to favor a low global carbon price. There are many political and sociological reasons that a low-emission country might prefer this, but we will motivate our example with just two economic reasons.

Low emission countries tend to be poor, and a poor country will likely find it cheaper to reduce emissions than will richer countries. Perhaps surprisingly, a lower marginal cost of abatement leads to a greater social cost for the total abatement undertaken. In fact a country with an extremely high marginal cost of abatement will hardly abate at all, and will spend very little on abatement. The social cost of abatement is roughly $A_{j} \cdot P / 2$, which declines with the amount of abatement undertaken. So the global burden of abatement will fall most heavily on those with the lowest cost of abatement. Second, a poor country may have a higher discount rate due to anticipated rapid growth and even due to poverty itself, so climate benefits in the distant future may be seen as less valuable. By adjusting the marginal cost of abatement down and marginal benefit from total abatement up, we will model a low-emission country that would favor a low global price target, were it not for the Green Fund.

We now define an example Green-Fund game with three countries. We call the high-emission-percapita country, the "U.S.," the average-emission country, "China," and the low-emission country, "India." Although the game is one-shot, in that it is not repeated, it is a two-stage game in that $G$ is determined and announced before the vote for $P^{T}$. The full specification is as follows:

1. The country with average per-capita emissions selects and announces $G$.

2. Each country votes for $P^{T}$ and the lowest value determines the global price target.

3. Countries receive payoff, $N B_{j}=b_{j} A-c_{j} A_{j}^{2}+G \cdot \Delta E_{j} \cdot P^{T}$.

The net benefit defined in Step 3 is the climate benefit of global abatement, minus the cost of domestic abatement due to implementing the global price target, plus Green-Fund revenues, which will be negative for the U.S. For comparison, Table 4 reports the outcome of the game without Step 1 and without the Green Fund included in the payoff. Then it reports the outcome of the Green-Fund game. 
Table 4. The Green-Fund Game Brings Increased Cooperation

\begin{tabular}{|c|c|c||c|c||c|c|c|c|}
\hline \multicolumn{3}{|c||}{} & \multicolumn{1}{c||}{ Without Green Fund } & \multicolumn{4}{c|}{ With Green Fund } \\
\hline Country & $\begin{array}{c}\text { Population } \\
\text { billions }\end{array}$ & $\begin{array}{c}e_{j} \\
\text { t/cap./yr }\end{array}$ & $\begin{array}{c}P^{T} \\
\text { Voted }\end{array}$ & $\begin{array}{c}A_{j} \\
\%\end{array}$ & $\begin{array}{c}P^{T} \\
\text { Voted }\end{array}$ & $\begin{array}{c}A_{j} \\
\%\end{array}$ & $\begin{array}{c}A_{j} \text { Cost } \\
\text { /cap./day }\end{array}$ & $\begin{array}{c}\text { G.F. Cost } \\
\text { /cap./day }\end{array}$ \\
\hline \hline U.S. & 0.3 & 18 & $\$ 30.96$ & $6.7 \%$ & $\$ 26.40$ & $17.6 \%$ & $11.5 \mathrm{C}$ & $4 \mathrm{C}$ \\
\hline China & 1.2 & 5.0 & $\$ 30.96$ & $6.7 \%$ & $\$ 30.96$ & $17.6 \%$ & $3.2 \mathrm{C}$ & 0 \\
\hline India & 1.0 & 1.1 & $\$ 10.00$ & $9.1 \%$ & $\$ 26.40$ & $24.0 \%$ & $1.0 \mathrm{C}$ & $-1.2 \mathrm{C}$ \\
\hline \hline World & 2.5 & 5.0 & $\$ 10.00$ & $6.9 \%$ & $\$ 26.40$ & $18.2 \%$ & $\$ 30 \mathrm{~B}$ & $\$ 4.3 \mathrm{~B}$ \\
\hline
\end{tabular}

Variable definitions: $e_{j}=$ emissions/capita, $P^{T}=$ global carbon price, $A_{j}=$ abatement. Units: Emissions are in tons/capita-year, abatement is a percent of emissions. Dollars are billions/year, and cents are per capita-year.

The cost and benefit coefficients for the game were first selected so that, without a Green Fund, all countries would vote for the optimal global carbon price of $\$ 30 /$ ton, and this would result in abatement of 20 percent. The coefficients for India were then adjusted as described above so that its preferred global target price would fall to $\$ 10 /$ ton. Because these changes reduced the marginal cost of abatement in India, the other two countries then prefer a global price of $\$ 30.96$ as shown in the first $P^{T}$ column. When the game begins, China selects a Green-Fund parameter, $G$, which causes the U.S. to vote for a lower $P^{T}$ and India to vote for a higher $P^{T}$, as shown in the second $P^{T}$ column. This results in the highest carbon price that the three countries can agree on within this game. The use of the Green Fund in the game increases abatement from $6.9 \%$ to $18.2 \%$.

This policy costs remarkably little. The U.S. pays just $\$ 17$ billion per year for abatement and Green Fund together. For China, the cost is five times less on a per-capita basis, and India achieves a net gain because of the Green Fund payments. None of this includes climate benefits. While a much more ambitious program will likely be needed in the future, what is needed now is a cooperative start on an efficient and sustainable policy. Scaling up this example to the current global population indicates GreenFund payments would be about $\$ 15$ billion dollars per year-far below the $\$ 100$ billion per year being discussed. And the $\$ 15$ billion would be paid only to countries that met their commitment to the global carbon price (Stoft 2009). That would make such payments more politically acceptable. For the United States, Green-Fund payments of roughly four cents per person per day might be manageable in the nottoo-distant future.

All of these example games, except in the section on cheating, have assumed that the rules are complied with and the payoff occurs as specified. In reality considerable attention must be paid to the problem of compliance, and the Green-Fund game has been designed with this in mind. In the game just presented, India would have a particularly strong motive for cooperation if Green-Fund payments were 
contingent on pricing performance. It gains both financially and through climate improvement. The threat of trade sanctions could be used against wealthier countries that attempt to renege. And of course, the concern that the treaty will unravel and leave all players worse off is a very real motivation for countries to continue cooperating. And all should want the treaty to remain intact since $P^{T}$ will be no higher than the level they would ideally wish it to be.

\section{Conclusion}

The proposed Green-Fund treaty contains several useful features. It solves a conceptual problem by suggesting that the right level for the Green Fund is the level that maximizes cooperation on climate policy. This makes sense when Green-Fund payments are tied to the outcome of international voting on the global price target. This arrangement also suggests who should be entrusted with the decision concerning the Green-Fund level - those who are affected least by Green-Fund payments and who are therefore motivated only by a desire for cooperation on climate policy. Countries who must pay into the Green Fund are protected by their say regarding the global carbon price, since Green-Fund payments are proportional to that price. Countries which require a high Green-Fund if they are to set a high carbon price are also protected by their say regarding the carbon price.

Linking Green-Fund disbursements to compliance with the global price, as suggested but not modeled, solves two problems: how to assure Green-Fund donors that they are gaining effective cooperation, and how to motivate those who receive funds to participate in an efficient global policy. Linking Green-Fund payments to emissions provides an additional incentive for all countries to reduce emissions.

But perhaps the most important point we would like to make is that the crux of the climate problem is not the "scientific" selection of emission caps good for the next fifty years. The real problem is cooperation in the most uncooperative of games - a public-goods game with many players facing distant and uncertain global payoffs. To solve this problem we should not look to the numerological focal points of popular movements. Instead we should look to the science of cooperation and to the economic models of self-interest to design a treaty for cooperation.

\section{References}

We thank Odd Godal for raising essential questions and for many helpful suggestions. Appendix, online at: www.global-energy.org/lib/11-01.

Barrett, Scott (1994). "Self-Enforcing International Environmental Agreements," Oxford Economic Papers, 46:878-94. 
Cooper, Richard N. (2008). "The Case for Charges on Greenhouse Gas Emissions," The Harvard Project on International Climate Agreements, Discussion Paper 08-10.

Cramton, Peter and Steven Stoft (2009). "Global Carbon Pricing: A Better Climate Commitment," Global Energy Policy Center Research Paper, 09-06. Available at: www.global-energy.org/lib.

Cramton, Peter and Steven Stoft (2010). "Price Is a Better Climate Commitment," The Economists' Voice, 7:1, Article 3. Available at: www.bepress.com/ev/vol7/iss1/art3.

Godal, Odd and Bjart J. Holtsmark (2011). "Permit Trading: Merely an Efficiency-Neutral Redistribution Away from Climate Change Victims?" Scandinavian Journal of Economics, forthcoming.

Helm, Carsten (2003). "International Emissions Trading with Endogenous Allowance Choices," Journal of Public Economics, 87, 2737-2747.

Hoel, Michael (1992). "Carbon Taxes: An international tax or harmonized domestic taxes?," European Economic Review 36, 400-406.

Holtsmark, Bjart J. and Dag Einar Sommervoll (2008). "International Emissions Trading in a Non-cooperative Equilibrium,” Discussion Papers 542, Research Department of Statistics Norway.

Rand, D.G., A. Dreber, T. Ellingsen, D. Fudenberg, and M.A. Nowak (2009). "Positive interactions promote public cooperation." Science 325, 1272-1275.

Schelling, Thomas C. (1960). The Strategy of Conflict. Cambridge, Massachusetts: Harvard University Press.

Stiglitz, Joseph E. (2010). "Overcoming the Copenhagen Failure,” http://www.projectsyndicate.org/commentary/stiglitz121.

Stoft, Steven (2009). "Flexible Global Carbon Pricing: A Backward-Compatible Upgrade for the Kyoto Protocol,” European Union Institute Working Papers, RSCAS 2009/35. Available at: cadmus.eui.eu/handle/1814/12097. 